\title{
Knowledge on Neonatal Danger Sign and Associated Factors among Mothers who Give Birth in Arerti General Hospital, Ethiopia from September, 2017- September 2018
}

\author{
Tsegahun Asfaw* \\ Department of Medical Laboratory Science, College of Medicine, Debre Berhan University, Debre Berhan, \\ Ethiopia
}

*Corresponding Author: Tsegahun Asfaw, Department of Medical Laboratory Science, College of Medicine, Debre Berhan University, Debre Berhan,Ethiopia.Email: tsegahun.asfaw12@gmail.com

\begin{abstract}
Newborn danger signs is a major challenge to negotiate successfully from intra-uterine to extrauterine life of the new-born. Danger signs in the neonatal period (0-28 days) are nonspecific and can be a manifestation of almost any newborn disease. The Aim of this study was to assess the level of knowledge of neonatal danger signs and associated factors among mothers who give birth. Facility based cross sectional study was conducted and data was collected by using structured questionnaire. A total of 190 mothers were involved and the data was analyzed by using SPSS version 21. P-value less than or equal to 0.05 was considered as statistically significant difference. The response rate was 182 (95.8\%). From all 182 mothers interviewed, only 87(47.8\%) of respondents were knowledgeable about Newborn danger sign. The most common source of information was health professionals $(92 \%)$ at the health facility. The most common danger sign recognized by mothers were persistent vomiting 136(74.7\%), Lethargy/unconsciousness 134 (73.6\%), Poor sucking/Unable to feed 127(69.8\%), but 53(29.1\%) of mothers did not heard about all of the neonatal danger signs. The odds of diploma/degree holders postnatal mothers were 57.75 times knowledgeable than as compared with those who were not literate. In general the magnitude of the knowledge of the postnatal mothers was good and majority of the health professionals had commitment to provide information on the neonatal dangers signs for mothers.
\end{abstract}

Keywords: Knowledge, Mothers, Neonatal Danger Sign

\section{INTRODUCTION}

In human life, the period from birth to 28 days of age is known as neonatal period [1]. Birth is a major challenge to the new-born to negotiate successfully from intra-uterine to extra-uterine life [2]. Newborn danger signs refer to presence of clinical signs that would indicate high risk of neonatal morbidity and mortality and the need for early therapeutic intervention.

Neonatal mortality remains high despite a declining proportion of deaths among children less than five years of age. Globally, every year, nearly $44 \%$ of all deaths in children under- five are among newborn infants. Near to $50 \%$ of the newborns die in their first day of life and $75 \%$ by seven days. According to 2012 report an estimated of 2.9 million neonates die annually in the first 4 weeks of life globally. Almost all $(99 \%)$ of these neonatal deaths occurred in low income and middle income countries with the highest rates occurring in sub-Saharan Africa (34 deaths per 1000 live births) accounts for 38 percent of global neonatal deaths [3]. In Ethiopia Mother's unprompted knowledge of newborn danger signs was low, with $29.3 \%$ of respondents able to name 3 or more danger signs out of a list of danger signs. There is very limited information about newborn care practices in Ethiopia because many key indicators are not currently measured by routine surveys like the Demographic and Health Survey [4]. Around 120,000 newborns die every year and the neonatal mortality rate is 37 per 1000 live births in Ethiopia, which is highest in the world [5]. Mothers are the primary caregivers of the newborn. Thus the knowledge of the mothers regarding newborn danger signs has a great influence on the health of the newborn [6]. Mothers need to know the danger signs of sick newborn. They can explain these signs to others or family member in a simple language so as to enable them to identify the danger signs and to seek early and prompt medical help. Hence, this study was carried out to assess mothers' knowledge and health care seeking behavior about neonatal danger sign. 


\section{Methods ANd Materials}

\subsection{Study Area}

The study was conducted at Arerti general hospital, Minjar Shenkora woreda. The hospital gives the services for all population in the district and neighboring woreda like Berihet district.

\subsection{Study Design and Period}

Facility based cross sectional study design was conducted from September, 2017- September 2018.

\subsection{Inclusion and Exclusion Criteria}

Mothers who were attending at Arerti general hospital and willing to participate were included while seriously ill and mothers with have mental problem were excluded. Based on this a total of 190 mothers were included.

\subsection{Operational Definition}

Neonatal Period: refers to the first 28 days of life

Early Neonatal Period: is the life of first 7 days Late Neonatal Period: is the life of days 8-28.

Neonatal Danger Signs: refer to the presence of clinical signs that would indicate high risk of neonatal morbidity and the need for early therapeutic intervention.

New Born Danger Sign: WHO definition were categorized as follows: i) Not feeding since birth or stopped feeding; ii) Convulsion; iii) Respiratory rate of 60 or more (fast breathing); iv) Severe chest in drawing (difficulty in breathing); v) Temperature of $\geq 37.5$ degree centigrade (hyperthermia); vi) Temperature $\leq$ 35.5 degree centigrade (hypothermia); vii) Only moves when stimulated or not even when stimulated (weakness or lethargy); viii) Yellow soles (sign of jaundice); ix) Umbilicus redness or draining pus, skin boils, or eyes draining pus (sign of local infection) and $\mathrm{x}$ ) Vomiting.

Knowledge: Factual information that the respondent knows regarding the newborn danger sign.

Table1. Sociodemographic characteristics of the respondents on the knowledge assessment on neonatal danger signs at Arerti general hospital, $(N=182)$

\begin{tabular}{|l|l|l|}
\hline Sociodemographic variables & Frequency (N=182) \\
\hline \multirow{4}{*}{ Age } & $18-24$ & $27(14.84 \%)$ \\
\cline { 2 - 3 } & $25-29$ & $73(40.11 \%)$ \\
\cline { 2 - 3 } & $30-34$ & $67(36.81 \%)$ \\
\cline { 2 - 3 } & $>=35$ years & $15(8.24 \%)$ \\
\hline \multirow{2}{*}{ Residency } & Urban & $52(28.6 \%)$ \\
\cline { 2 - 3 } & Rural & $130(71.4 \%)$ \\
\hline Religion & Orthodox & $170(93.4 \%)$ \\
\cline { 2 - 3 } & Other & $12(6.6 \%)$ \\
\hline Ethnicity & Amhara & $168(92.3 \%)$ \\
\hline
\end{tabular}

Knowledgeable on New born danger signs; a woman was considered as knowledgeable on newborn danger signs if she spontaneously mentioned three or more WHO newborn danger signs.

Not knowledgeable on New born danger signs; a woman was considered as Not knowledgeable on newborn danger signs if she spontaneously mentioned less than three WHO newborn danger signs.

\subsection{Data Collection Methods and Analysis}

Structured questionnaire was developed with local language. Data was collected trained nurse through interviewing. Data was analyzed using SPSS version 21 and the prevalence of mothers' knowledge on each danger signs of neonates was determined and presented by using tables, reports and graphs.

\subsection{Ethical Clearance}

Ethical approval was obtained by Minjar Shenkora worda administrative office and official permission was obtained from head department of Arerti general hospital.

\section{RESULT}

\subsection{Sociodemographic Characteristics of the Respondents}

A total of $182(95.8 \%)$ mothers were volunteer and interviewed for the assessment of their knowledge on neonatal danger signs. 73(40.11\%) mothers were between the age of 25-29 years and $130(71.4 \%)$ lives in the rural area. From all respondents $170(93.4 \%)$ were orthodox Christian, 168 (92.3\%) were also ethically Amhara and most of them are not literate. From 182 study subjects $24(13.2 \%)$ were Employed, $29(15.9 \%)$ were diploma/degree holders but 61(33.5\%) were complete secondary school. Only $159(87.4 \%)$ of postnatal mothers were had a history of pregnancy more than one (Table 1). 
Knowledge on Neonatal Danger Sign and Associated Factors among Mothers who Give Birth in Arerti General Hospital, Ethiopia from September, 2017- September 2018

\begin{tabular}{|l|l|l|}
\hline \multirow{4}{*}{ Educational level of mothers } & Other & $14(7.7 \%)$ \\
\hline \multirow{4}{*}{ Husbands level of education } & literate (up to 8 grade) & $37(20.3 \%)$ \\
\cline { 2 - 3 } & complete secondary school & $83(45.6 \%)$ \\
\cline { 2 - 3 } & Diploma/Degree holder & $39(21.4 \%)$ \\
\cline { 2 - 3 } & Illiterate & $23(12.7 \%)$ \\
\hline \multirow{5}{*}{ Mothers occupation } & literate (up to 8 grade) & $71(39.0 \%)$ \\
\cline { 2 - 3 } & complete secondary school & $61(33.5 \%)$ \\
\cline { 2 - 3 } & Diploma/Degree holder & $29(15.9 \%)$ \\
\cline { 2 - 3 } & not literate(can't read and write) & $21(11.5 \%)$ \\
\hline \multirow{5}{*}{ Family size } & Employed(governmental or private) & $24(13.2 \%)$ \\
\cline { 2 - 3 } & Student & $12(6.6 \%)$ \\
\cline { 2 - 3 } & Merchant and (private work) & $32(17.9 \%)$ \\
\cline { 2 - 3 } & Farmer & $86(47.2 \%)$ \\
\cline { 2 - 3 } & House wife & $28(15.4 \%)$ \\
\hline Gravidity & $<=3$ & $58(31.9 \%)$ \\
\cline { 2 - 3 } & $>=4$ & $124(68.1 \%)$ \\
\hline Parity of the mother & Primigravida & $23(12.6 \%)$ \\
\cline { 2 - 3 } & Multigravida & $159(87.4 \%)$ \\
\hline & $1-3$ children & $89(48.9 \%)$ \\
\cline { 2 - 3 } & $>3$ children & $67(36.8 \%)$ \\
\hline
\end{tabular}

Out of 182 post natal mothers mojority of them were married(40.1\%) and $14.3 \%$ of them were not married (Figure 1).

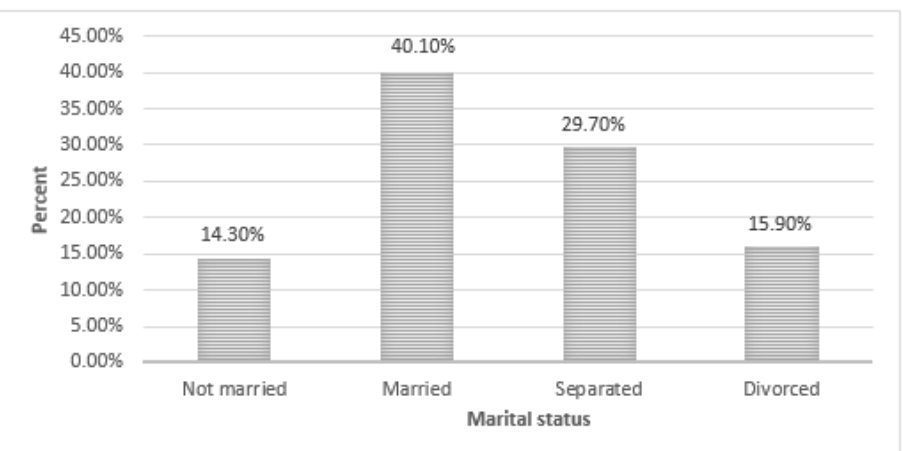

Figure1. Marital status of postnatal mothers in Arerti general hospital $(N=182)$

Out of the 182 respondents $33 \%$ of the mothers had an estimated monthly income of $<500$ birr per month and $17 \%$ of them had got 500-1000 birr per month (Figure 2).

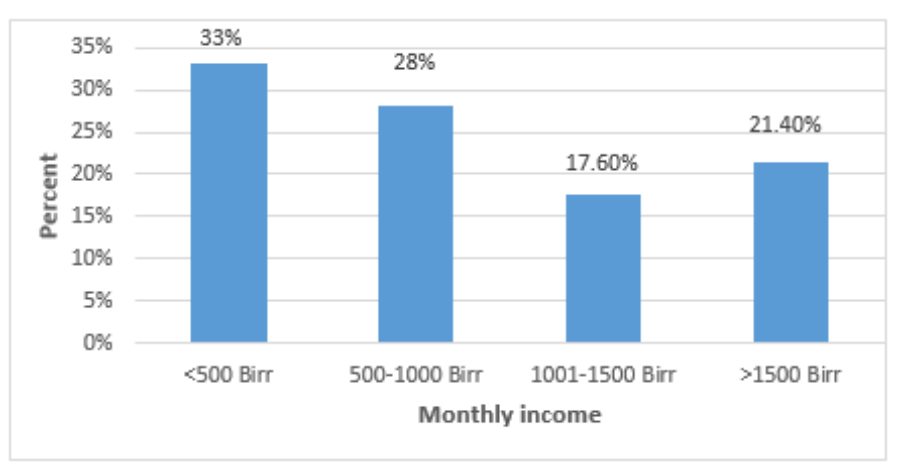

Figure2. Estimated monthly incomes of postnatal mothers at Arerti general hospital

\subsection{Results of Maternal Health Service Utilizations}

Among 182 mothers 53(28.6\%) of the pregnant mothers had an access to hospital, 67(36.8\%) had access to health center 34(18.7\%), 28(15.4\%) had an access to health posts and private clinics respectively. All of the mothers (100\%) were vaccinated tetanus toxin vaccine during their ANC visits. During ANC follow up in the health institution $153(84.1 \%$ ) of the mothers were got advise (counseling on the neonatal danger signs) and the remaining $29(15.9 \%)$ of mothers were not got counseling or not remember. Among 182 mothers, $43 \%$ had $1-2$ visits to the health institution (Figure 3). 


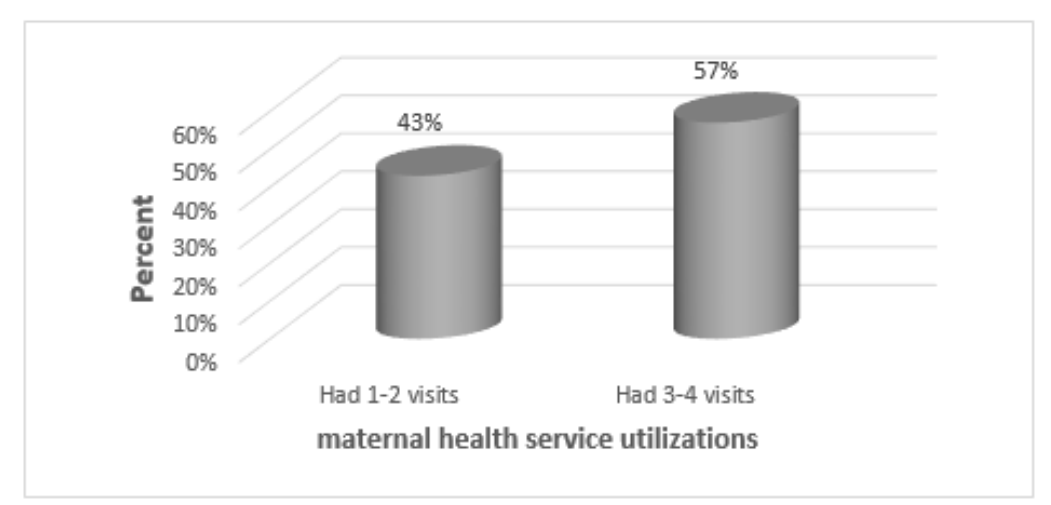

Figure3. Previous ANC visits of postnatal mothers at Areti general hospital

From 182 mothers $14 \%$ of them were borne the last neonate at the health institution through instrumental assisted delivery while $81 \%$ were give birth through Spontaneous vaginal delivery (Figure 4)

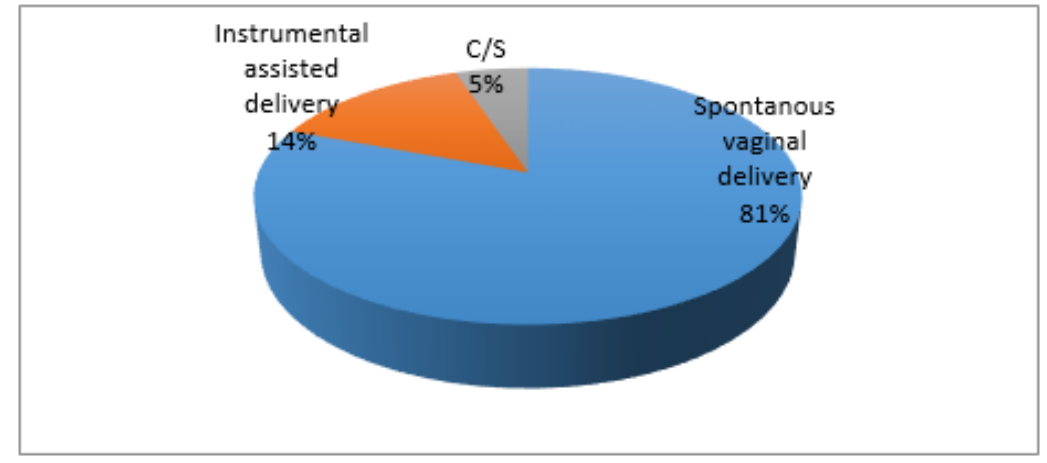

Figure4. Mode of delivery of postnatal mothers at Arerti general hospital

\subsection{Source of Information for Postnatal \\ health professionals but only 5\% had got} Mothers about Neonatal Danger Signs information from radio/TV. (Figure 5).

Among 182 postnatal mothers $92 \%$ had got information about neonatal danger sign from

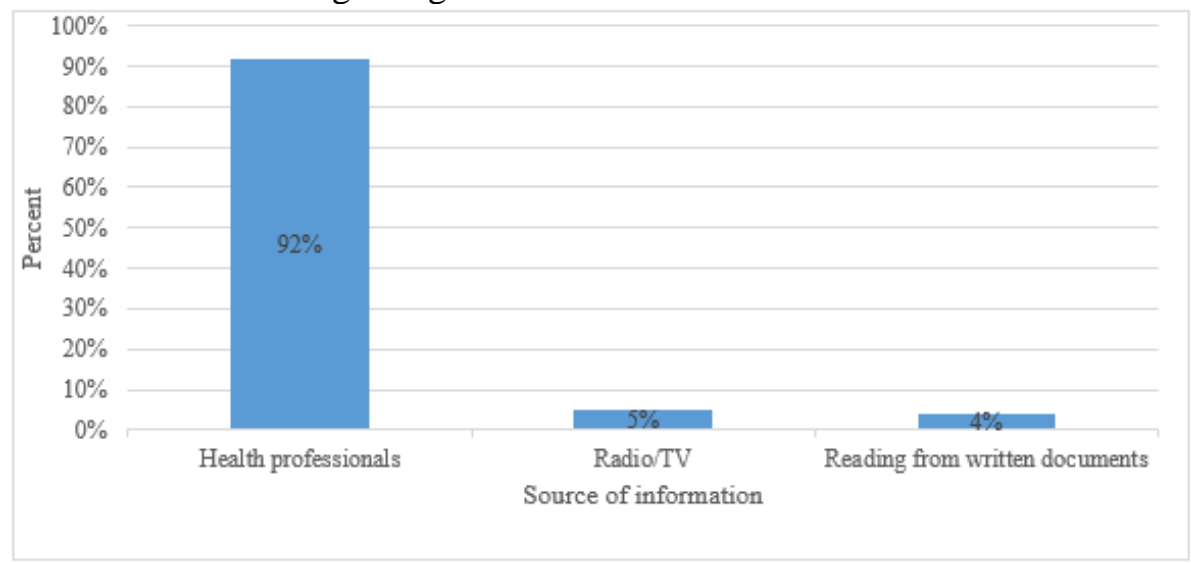

Figure5. Assessment of the source of information on the neonatal danger sign by postnatal mothers at Arerti general hospital

Among 182 postnatal mothers 29 (15.9\%) had not heard and the other remaining $153(84.1 \%)$ had heard about neonatal danger signs.

However, only 87 (47.8\%) of respondents were knowledgeable about Newborn danger sign. The most common danger sign recognized by mothers were persistent vomiting 136 (74.7\%), Lethargy/unconsciousness 134 (73.6\%), Poor sucking/Unable to feed $127(69.8 \%)$, but 53 (29.1\%) of mothers did not heard about all of the neonatal danger signs. The most common source of information was health professionals (92\%) through health extension program (Figure 6). 
Knowledge on Neonatal Danger Sign and Associated Factors among Mothers who Give Birth in Arerti General Hospital, Ethiopia from September, 2017- September 2018

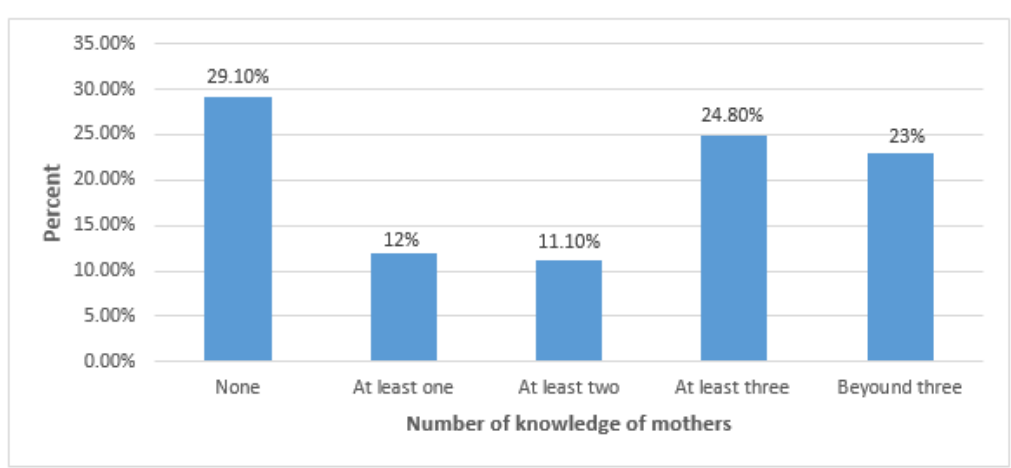

Figure6. Assessment of the knowledge of postnatal mothers that they mentioned about neonatal danger signs at Arerti general hospital

From the study subjects interviewed $110(60.4 \%)$ of postnatal mothers did not recognize Jaundice as a neonatal danger sign and $98(53.8 \%)$ of them also did not recognize hypothermia as neonatal danger signs (Table 2).

Table2. Knowledge postnatal mothers on the neonatal danger signs at Arerti general hospital

\begin{tabular}{|l|l|l|}
\hline Variable & Yes & Frequency(N=182) \\
\cline { 2 - 3 } & No & $127(69.8 \%)$ \\
\hline \multirow{2}{*}{ Poor sucking/Unable to feed } & Yes & $55(30.2 \%)$ \\
\cline { 2 - 3 } & No & $95(52.2 \%)$ \\
\hline \multirow{2}{*}{ Fast breathing(difficulty of breathing } & Yes & $87(47.8 \%)$ \\
\cline { 2 - 3 } & No & $113(62.1 \%)$ \\
\hline \multirow{2}{*}{ Chest in drawing } & Yes & $69(37.9 \%)$ \\
\cline { 2 - 3 } & No & $67(36.8 \%)$ \\
\hline \multirow{2}{*}{ Lethargy/unconsciousness } & Yes & $115(63.2 \%)$ \\
\cline { 2 - 3 } & No & $134(73.6 \%)$ \\
\hline \multirow{2}{*}{ Hypothermia } & Yes & $48(26.4 \%)$ \\
\cline { 2 - 3 } & No & $84(46.2 \%)$ \\
\hline Fever & Yes & $98(53.8 \%)$ \\
\cline { 2 - 3 } & No & $93(51.1 \%)$ \\
\hline Persistent vomiting & Yes & $89(48.9 \%)$ \\
\cline { 2 - 3 } & No & $136(74.7 \%)$ \\
\hline \multirow{2}{*}{ Jaundice } & Yes & $46((25.3 \%)$ \\
\cline { 2 - 3 } & No & $72(39.6 \%)$ \\
\hline Not recognize all of the above & & $53(29.1 \%)$ \\
\hline
\end{tabular}

\subsection{Association of the Access of Information and Knowledge of Mothers on Neonatal Danger Signs}

The odds of knowledge of postnatal mothers on the neonatal danger sign were 4.3125 times knowledgeable as compared with those postnatal mothers who had no information. The odds of being living in urban area was 2.7076 times knowledgeable than from those postnatal mothers living in rural areas.

The odds of the knowledge of postnatal mothers who complete secondary school were 10.7561

Table3. Associations of the postnatal mothers with different independent variables at Arerti general hospital

\begin{tabular}{|c|c|c|c|c|c|c|}
\hline & \multirow[t]{2}{*}{ Knowledgeable } & \multirow{2}{*}{$\begin{array}{l}\text { Not } \\
\text { knowledgeable }\end{array}$} & \multirow[t]{2}{*}{ OR } & \multicolumn{2}{|l|}{$95 \% \mathrm{CI}$} \\
\hline & & & & & Lower limit & Upper limit \\
\hline \multirow{2}{*}{$\begin{array}{lrr}\text { Heard } & \text { about } & \text { neonatal } \\
\text { dangers } & \text { signs } & \text { from } \\
\text { different sources } & \end{array}$} & Yes & 81 & 72 & \multirow[t]{2}{*}{4.3125} & \multirow[t]{2}{*}{1.6629} & \multirow[t]{2}{*}{11.1836} \\
\hline & No & 6 & 23 & & & \\
\hline Residency & & 47 & 7 & 2.7076 & 1.3681 & 5.3588 \\
\hline
\end{tabular}

times knowledgeable than as compared with those who were not literate.

The odds of diploma/degree holders postnatal mothers were 57.75 times knowledgeable than as compared with those who were not literate. The odds of postnatal mothers who complete up to grade 8 were 3.8889 times knowledgeable than as compared with those who were not literate. The odds of the mothers who had 1-3 children were 1.9707 times knowledgeable as compared with the postnatal mothers who had three or more than three children (Table 3). 
Knowledge on Neonatal Danger Sign and Associated Factors among Mothers who Give Birth in Arerti General Hospital, Ethiopia from September, 2017- September 2018

\begin{tabular}{|c|c|c|c|c|c|c|}
\hline & Rural & 54 & 76 & & & \\
\hline \multirow[t]{4}{*}{ Age } & $18-24$ & 15 & 12 & 0.3125 & 0.0715 & 1.3665 \\
\hline & $25-29$ & 29 & 44 & 0.1648 & 0.0427 & 0.6351 \\
\hline & $30-34$ & 31 & 36 & 0.2153 & 0.0556 & 0.8331 \\
\hline & $>=35$ years & 12 & 3 & & & \\
\hline \multirow{4}{*}{$\begin{array}{l}\text { Educational } \\
\text { level of } \\
\text { mothers }\end{array}$} & $\begin{array}{l}\text { literate (up to } 8 \\
\text { grade) }\end{array}$ & 36 & 1 & 3.8889 & 0.7682 & 19.6859 \\
\hline & $\begin{array}{l}\text { complete } \\
\text { secondary school }\end{array}$ & 42 & 41 & 10.7561 & 2.3692 & 48.8319 \\
\hline & $\begin{array}{l}\text { Diploma/Degree } \\
\text { holder }\end{array}$ & 33 & 6 & 57.75 & 10.6424 & 313.3744 \\
\hline & Illiterate & 2 & 21 & & & \\
\hline \multirow[t]{2}{*}{ Gravid } & Primigravida & 8 & 15 & 0.5401 & 0.2168 & 1.3453 \\
\hline & Multigravida & 79 & 80 & & & \\
\hline \multirow[t]{2}{*}{ Parity } & $\begin{array}{l}1-3 \text { had } 1-3 \\
\text { children }\end{array}$ & 56 & 33 & 1.9707 & 1.0342 & 3.755 \\
\hline & $>=3$ children & 31 & 36 & & & \\
\hline
\end{tabular}

\section{DISCUSSION}

In this study the level of knowledge of postnatal mothers on the neonatal danger signs that mentioned three or above problems among nine were $87(47.8 \%)$, which is greater than study conducted in Uganda where only $14.8 \%$ can name at least two signs. The most recognized neonatal danger sign in this study was persistent vomiting 136 (74.7\%), Lethargy/ unconsciousness 134 (73.6\%), Poor sucking/Unable to feed 127 $(69.8 \%)$, but $53(29.1 \%)$ of mothers did not heard about all of the neonatal danger signs. This might be due the commitment of the health professionals [7].

Majority of mothers $136(74.7 \%)$ recognize persistent vomiting as a neonatal danger sign which is different from study conducted in Periurban Wardha, India where 55(76.4\%) mothers identified fever as newborn danger signs. This study also revealed that $113(73.6 \%), 127$ $(69.8 \%)$ and $134(73.6 \%)$ mothers identified difficulty in breathing, poor sucking and lethargy/unconsciousness as newborn danger signs respectively; which was greater than the study conducted at Peri-urban Wardha, India, where $29(40.3 \%), 16(22.2 \%)$ and $10(13.9 \%)$ mothers identified difficulty in breathing, poor sucking and lethargy/unconsciousness respectively. This difference might be due to accessibility of information and previous history of ANC follow up [8].

In this study the knowledge of the post-natal mothers on neonatal danger sign was $87(47.8 \%$ ) which was lower than the study conducted in Mangalore, India where $43(62 \%)$ had good knowledge. This might be due to health professional's competency to provide information related to neonatal danger signs during $\mathrm{ANC}$ and PNC follow up to mothers [9].
And also lower than the study conducted at randomly selected 16 governmental health centers of Addis Ababa, Ethiopia. However, most of the respondents $59.8 \%$ were a moderately knowledgeable of neonatal danger signs while $24.2 \%$ were highly knowledgeable, and $16 \%$ were poorly knowledgeable and 280 $(77.1 \%)$ mothers knew at least one neonatal danger sign. The most commonly recognized neonatal danger signs was persistent vomiting 136 (74.7\%), Lethargy/unconsciousness 134 (73.6\%), Poor sucking/Unable to feed 127 $(69.8 \%)$, which was different from the most common mentioned neonatal danger signs Diarrhea 58.9\%, Persistent vomiting, $43.9 \%$, and Fever, $32.9 \%$ in the study conducted at 16 selected hospitals in Addis Ababa. This difference might be study area that increases the probability of getting knowledgeable mothers [10].

The result of this study showed 87(47.8\%) mothers mentioned three and above neonatal dangers sign which was greater than study conducted in Ethiopia where mothers (18.2\%) who had knowledge of three or more neonatal danger signs (good knowledge). This difference might be the accessibility of information to mothers on the neonatal danger signs [11]. The postnatal mothers level of knowledge $(47.8 \%)$ was lower than from Community based cross sectional study conducted in Chencha District, Southern Ethiopia where 50.3\% of mothers had good level of knowledge who knows three or more neonatal danger signs. This might be due to the research study design difference [12].

\section{CONCLUSION AND RECOMMENDATION}

The knowledge of the mothers about the neonatal dangers signs was good and majority of the 
health professionals had commitment to provide them information while they give antenatal and postnatal care services. Majority of the mothers had antenatal care follow up during pregnancy and all of them were vaccinated for tetanus toxin. However, intensive counseling and information services on newborn danger sign should give emphasis for those mothers having low income and urban residence, who attend health facility for antenatal care, delivery and postnatal care service. Mather to mother education should also strengthen among the society.

\section{AUTHORS' CONTRIBUTIONS}

TA-collect and analyzed the data. TA- wrote and approve the manuscript.

\section{ACKNOWLEDGMENT}

I wouid like to thank nurse and midwifery staffs and head or director of Arerti general hospital for their help during data collection process.

\section{REFERENCES}

[1] World Health Organization: Neonatal Danger Sign, 2014

[2] Kanchan B, Raj Kumari SD, Gomathi B. Effectiveness of an 'Instructional Teaching Programme' (ITP) on the knowledge of postnatal mothers regarding new-born care. $\mathrm{Hu}$ Li ZaZhi. 2013, 3: 231-237.

[3] UN Inter-agency Group for Child Mortality Estimation (IGME). Levels and trends in child mortality: report 2013. New York, NY: UNICEF, 2013.

[4] Ethiopia Demographic and Health Survey, 2011.

[5] Central Statistical Agency and ICF International; 2012.

[6] Jacob Sandberg mail, Karen OdbergPettersson, Gustav Asp, Jerome Kabakyenga, AnetteAgardh
Inadequate Knowledge of Neonatal Danger Signs among Recently Delivered Women in Southwestern Rural Uganda: A Community Survey Published: May13, 2014 DOI: 10.1371/ journal. pone. 0097253.

[7] Awasthi S, Verma T, Agarwal M (2006) Danger signs of neonatal illnesses: perceptions of caregivers and health workers in northern India. Bulletin of the World Health Organization 84(10): 819-826. doi: 10.2471/blt.05.029207.

[8] Danger AR, Deshmukh PR, Garg BS (2009) Awareness and health care seeking for newborn danger signs among mothers in peri-urban Wardha. Indian journal of pediatrics 76(7): 691693. doi: 10.1007/s12098-009-0106

[9] Dominic A. et al., Knowledge On Warning Signs of New Born Illness Among The Mothers With A View To Develop An Information Booklet, Karnataka, INDIA American International Journal of Research in Humanities, Arts and Social Sciences, 20134(1): pp92-94.

[10] Fisseha Mulatu. Assessment of knowledge and health care seeking behavior about neonatal danger signs among mothers visiting immunization unit in selected governmental health centers Addis Ababa, Ethiopia. Journal of pediatrics; November 2013-june 2014:30-34.

[11] Nigatu SG, Worku AG, Dadi AF. Level of mother's knowledge about neonatal danger signs and associated factors in North West of Ethiopia: a community based study BMC Res Notes. 2015, 8:309. DOI 10.1186/s13104-0151278-6

[12] Abera Mersha, Nega Assefa, Kedir Teji, Agegnehu Bante, Shitaye Shibiru. Mother's Level of Knowledge on Neonatal Danger Signs and Its Predictors in Chencha District, Southern Ethiopia. American Journal of Nursing Science. Vol. 6, No. 5, 2017, pp. 426-432. doi: 10.11648/j.ajns.20170605.17

Citation: Tsegahun Asfaw, Knowledge on Neonatal Danger Sign and Associated Factors among Mothers who Give Birth in Arerti General Hospital, Ethiopia from September, 2017- September 2018. ARC Journal of Nursing and Healthcare. 2019; 5(3):1-7. doi: dx.doi.org/ 10.20431/2455-4324.0503001.

Copyright: () 2019 Authors. This is an open-access article distributed under the terms of the Creative Commons Attribution License, which permits unrestricted use, distribution, and reproduction in any medium, provided the original author and source are credited. 